\title{
Urolithiasis: Presentation and Surgical Outcome at a Tertiary Care Hospital in Ethiopia
}

This article was published in the following Dove Press journal:

Research and Reports in Urology

\author{
Seid Mohammed' \\ Binyam Yohannes ${ }^{2}$ \\ Alemayehu Tegegne' \\ Kirubel Abebe $\mathbb{D D}^{2}$ \\ 'Urology Unit, Department of Surgery, \\ St. Paul's Hospital Millennium Medical \\ College, Addis Ababa, Ethiopia; \\ ${ }^{2}$ Department of Surgery, St. Paul's \\ Hospital Millennium Medical College, \\ Addis Ababa, Ethiopia
}

Background: The prevalence of urolithiasis is on a rising trend in tropical and sub-Saharan African countries. The treatment options and data on the surgical outcome are limited in our country. This study was designed to assess the clinical presentation, surgical management and outcome of patients operated on for urolithiasis.

Patients and Materials: A retrospective study of all patients admitted and operated for urolithiasis at St. Paul's hospital millennium medical college (SPHMMC) from July, 2016 to December, 2017 was conducted. Factors associated with surgical outcome were identified with binary logistic regression.

Results: Urolithiasis constituted 247 (30.0\%) of 824 urologic admissions. Of these, 202 (Male:Female $=2: 1$ ) patients were investigated. The mean age was $37.1 \pm 14.4$ years (range, 10-85 years). The mean duration of illness was $16.7 \pm 18.7$ months and the commonest presenting symptom was isolated flank pain $(97,48.0 \%)$. A majority of the patients (186, 92.1\%) had upper tract stones of which 96 (51.6\%) were renal stones. More than two-third $\mathrm{s}(164,81.2 \%)$ of the patients had complications at presentation, and hydronephrosis (148, $73.3 \%)$ was the major one. Half of the patients $(104,51.5 \%)$ were treated with endoscopic procedures, $88(43.6 \%)$ with open stone surgery and in $10(4.9 \%)$ patients both were performed. Nephrectomy was done to $15(7.4 \%)$ patients. Intraoperative and postoperative complications were noted in $16(7.9 \%)$ and $26(12.9 \%)$ patients, respectively. These complications were higher in patients with comorbid illness (AOR $=2.44 ; 95 \%$ CI 1.12-5.31; $\mathrm{p}=$ 0.024). Complete stone clearance was achieved in more than half of the clients $(114,61.0 \%)$. Multiple stones $(\mathrm{AOR}=8.33 ; 95 \%$ CI 2.53-27.43; $\mathrm{p}<0.0001)$ and endoscopic procedures $(\mathrm{AOR}=4.17 ; 95 \%$ CI $1.57-10.71 ; \mathrm{p}=0.003)$ had significant association with incomplete stone clearance.

Conclusion: Patients' presentation in this review was not different from studies elsewhere. Endoscopic procedures are emerging in our set up; however, it was significantly associated with incomplete stone clearance. Strategies to improve outcome (stone clearance) need to be implemented accordingly.

Keywords: urolithiasis, presentation, surgical outcome, Ethiopia

\section{Introduction}

Urolithiasis is defined as the formation or occurrence of stone(s) at any level of the urinary tract (kidney, ureter, bladder and urethra). ${ }^{1-5}$ It is the third most common pathology affecting the urinary tract and it has been described since antiquity. ${ }^{6-10}$

The incidence and prevalence of a urinary stone vary with geographic location, race, age, occupation, and sex. Worldwide the prevalence is estimated to be $1-5 \%$ and higher in developed nations $(2-13 \%)$ than developing ones $(0.5-1 \%)$. ${ }^{6,7,11,12}$ Even if it is more prevalent in countries located in the "Afro-Asian stone forming
Correspondence: Kirubel Abebe

Department of Surgery, St. Paul's Hospital Millennium Medical College, Addis Ababa

I27I, Ethiopia

Tel +25I 92II43772

Email Kirumel@yahoo.com

Research and Reports in Urology 2020:I2 623-63I 
belt", it is on a rising trend in tropical and sub-Saharan African countries due to global climate change and growing socio-economic status as manifested by westernized diet and lifestyle. ${ }^{1,4,5,7,12-15}$ This has also shifted the site of stone formation from lower tract to the upper tract and the disease once limited to men is increasingly gender blind. $^{6-8}$

The incidence of urolithiasis peaks in the 4th to 6th decade of life and the presentation may range from no or mild symptom to life-threatening sepsis and obstructive renal failure. $6,7,9$

The treatment options include watchful waiting, stone dissolution, medical expulsive therapy, extracorporeal treatment, uroendoscopic interventions and open stone surgery. $^{12,16}$ Overall, the specific treatment relies on stone composition, site, size, number, patients' general condition and preference, and institutional capacity. ${ }^{17-19}$

Despite the advancement of minimally invasive and noninvasive management of stone disease, which has become the gold standard treatment, open stone surgery remains the technique of choice in most developing countries. . $3,16,20,21$ This reflects the lack of trained professionals and endourologic instruments. ${ }^{16,22-24}$

As Ethiopia is a fast-growing, sub-Saharan Africa country, located near to the Afro-Asian stone belt, the burden is expected to be rising and becoming a public health issue. ${ }^{5}$ However, data are scarce and the treatment options are limited. Hence this study assesses the clinical presentation, surgical management and outcome of patients operated on for urolithiasis.

\section{Patients and Materials}

A retrospective cross-sectional study was conducted to assess the clinical presentation, surgical management and outcome of all patients who were admitted and operated on for urolithiasis between July 1st 2016 and December 31st 2017 at St. Paul's hospital millennium medical college (SPHMMC). SPHMMC is a tertiary care teaching hospital found in Addis Ababa, Ethiopia which serves as a referral center for patients from all over the country. The urology unit is under the department of surgery with a capacity of 21 beds and each year more than 500 major urologic procedures are performed.

Ward and operation theater registries were used to identify all urologic admissions as well as subjects who were admitted and operated on for urolithiasis during the study period. A total of 247 cases of urolithiasis were operated on in 18 months and of these $202(81.8 \%)$ medical records were retrieved and investigated for reasons such as missed medical records and incomplete data. A pretested data collection format was employed to collect information regarding patient's socio-demographic characteristics, clinical presentation, preoperative workup, type of surgical management, intraoperative findings and surgical outcome (complication, mortality and stone clearance).

Data were checked for completeness, accuracy, consistency then coded and entered into SPSS version 23 for analysis. Binary logistic regression was used to identify factors associated with surgical outcome (stone clearance and operative complications). Variables with a p-value $<0.3$ during a bivariate analysis were further subjected to a multivariate analysis and considered significant at $\mathrm{p}$-values $<0.05$. Fifteen patients with unknown stone clearance status were excluded during the analysis of factors associated with incomplete clearance. Results were presented using texts, tables and central tendency statistics.

This study was conducted in accordance with the Declaration of Helsinki and was approved by SPHMMC institutional review board (IRB). Since patients were not contacted and data were extracted retrospectively from patients' chart, the IRB waived the study without patients' consent. All the data were anonymized and confidentiality was kept throughout the study.

\section{Results}

Among 824 urologic admissions, 247 (30.0\%) were for urolithiasis. Of these,202 (81.8\%) cases were studied. Males constituted 135 (66.8\%) admissions with a male to female ratio of $2: 1$. The mean age was $37.1 \pm 14.4$ years (range, 10-85 years) and nearly one third $(61,30.2 \%)$ of patients were aged between 20 and 29 years. The prevalence of urolithiasis was only higher in females $(61.5 \%$ vs $38.5 \%$ ) in the second decade of life, otherwise, males predominate. In general, urolithiasis was more prevalent $(147,72.8 \%)$ in the age group 20-49 years. One third (68, $33.7 \%$ ) of patients were civil servants and most (83, 41.1\%) came from Addis Ababa (Table 1).

The mean duration of illness was $16.7 \pm 18.7$ months (range, 1-120 months). Flank pain alone (97, 48.0\%) and flank pain with hematuria $(55,27.2 \%)$ were the two leading presenting symptoms. Comorbidities were identified in 56 $(27.7 \%)$ patients and hypertension $(43,21.2 \%)$ was the commonest (Table 2).

Ultrasound was the main diagnostic imaging obtained in all patients followed by intravenous pyelogram (IVP) (153, 75.7\%), Computed tomography (CT) scan (40, 
Table I Sociodemographic Characteristics of Patients Admitted and Operated On for Urolithiasis at St. Paul's Hospital Millennium Medical College, Addis Ababa, Ethiopia, from July 2016 to December 2017

\begin{tabular}{|c|c|c|c|}
\hline \multirow[t]{2}{*}{ Variables } & \multicolumn{2}{|l|}{ Sex } & \multirow[t]{2}{*}{ Total n (\%) } \\
\hline & Male n (\%) & Female n (\%) & \\
\hline \multicolumn{4}{|l|}{ Age } \\
\hline $10-19$ & $5(38.5)$ & $8(61.5)$ & $13(6.4)$ \\
\hline $20-29$ & $42(68.9)$ & $19(31.1)$ & $6 I(30.2)$ \\
\hline $30-39$ & $27(62.8)$ & $16(37.2)$ & $43(2 \mid .3)$ \\
\hline $40-49$ & $3 I(72.1)$ & $12(27.9)$ & $43(21.3)$ \\
\hline $50-59$ & $15(60.0)$ & $10(40.0)$ & $25(12.4)$ \\
\hline $60-69$ & II(84.6) & $2(15.4)$ & $13(6.4)$ \\
\hline$\geq 70$ & $4(100)$ & $0(0)$ & $4(2.0)$ \\
\hline \multicolumn{4}{|l|}{ Region/Address } \\
\hline Addis Ababa & $55(66.3)$ & $28(33.7)$ & $83(4 I . I)$ \\
\hline Oromia & $42(68.9)$ & $19(31.1)$ & $61(30.2)$ \\
\hline SNNP & $24(75.0)$ & $8(25.0)$ & $32(15.8)$ \\
\hline Amhara & $13(54.2)$ & II (45.8) & $24(11.9)$ \\
\hline Tigray & $I(50.0)$ & $I(50.0)$ & $2(1.0)$ \\
\hline \multicolumn{4}{|l|}{ Occupation } \\
\hline Civil servant & $50(72.5)$ & $19(27.5)$ & $69(34.1)$ \\
\hline Trader & $25(83.3)$ & $5(16.7)$ & $30(14.8)$ \\
\hline Unknown & $16(64.0)$ & $9(36.0)$ & $25(12.4)$ \\
\hline Student & $13(59.1)$ & $9(40.9)$ & $22(10.9)$ \\
\hline Farmer & $19(90.5)$ & $2(9.5)$ & $21(10.4)$ \\
\hline Factory workers & $13(72.2)$ & $5(27.8)$ & 18(8.9) \\
\hline Housewife & - & $17(100)$ & $17(8.4)$ \\
\hline
\end{tabular}

Table 2 Presenting Symptoms and Associated Comorbidities in Patients Operated On for Urolithiasis at St. Paul's Hospital Millennium Medical College, Addis Ababa, Ethiopia, from July 2016 to December 2017

\begin{tabular}{|l|l|}
\hline Variables & Total $\mathbf{n}$ (\%) \\
\hline Presenting symptoms & \\
Flank pain & $97(48.0)$ \\
Flank pain and Hematuria & $55(27.2)$ \\
Flank pain, Hematuria and Dysuria & $32(15.8)$ \\
Hematuria & $7(3.5)$ \\
Dysuria & $6(3.0)$ \\
Acute urinary retention & $3(1.4)$ \\
Hematuria and Dysuria & $2(1.0)$ \\
\hline Comorbidities & \\
No comorbidity & $146(72.3)$ \\
Hypertension & $27(13.4)$ \\
Hypertension and Diabetes Mellitus & $14(6.9)$ \\
Diabetes Mellitus & $7(3.5)$ \\
HIV Infection* & $6(3.0)$ \\
Hypertension and HIV Infection & $2(1.0))$ \\
\hline
\end{tabular}

Abbreviation: *HIV, human immunodeficiency virus.
$19.8 \%$ ) and X-ray of the kidney-ureters-bladder (KUB) $(23,11.4 \%)$.

Majority of the stones were upper tract $(186,92.1 \%)$ out of which $96(47.5 \%)$ were renal stones, 62 (30.7\%) were ureteric stones and $28(13.9 \%)$ were concomitant renal and ureteric stones. Regarding the anatomic location, the left kidney $(43,21.3 \%)$ was the commonest site followed by right kidney $(39,19.3 \%)$ and left ureter $(33$, $16.3 \%)$. Overall, urolithiasis occurred more on the left side $(102,50.5 \%)$ than the right $(87,43.1)$ (Table 3$)$.

Among the ureteric stones, $28(45.2 \%)$ found in the proximal ureter, $27(43.5 \%)$ in the mid-ureter and 7 $(11.3 \%)$ in the distal ureter.

Of the patients, 95 (47.0\%) had a single stone, 67 (33.2\%) had multiple stones and $40(19.8 \%)$ had a staghorn stone.

Complications at presentation were seen in more than two-thirds $(164,81.2 \%)$ of the patients. Hydronephrosis $(148,73.3 \%)$ was the major one followed by renal failure $(10,4.9 \%)$ and pyonephrosis $(6,3.0 \%)$.

Of the patients, most $(104,51.5 \%)$ were treated with endoscopic procedures, 88 (43.6\%) with open stone surgery and in $10(4.9 \%)$ patients both open and endoscopic interventions were performed. The most frequently carried out procedures include pyelolithotomy $(34,35.4 \%)$ for renal stone, ureterorenoscopy (URS) $(56,90.3 \%)$ for ureteric

Table 3 Anatomic Locations of Stones in Patients Admitted and Operated On for Urolithiasis at St. Paul's Hospital Millennium Medical College, Addis Ababa, Ethiopia, from July 2016 to December 2017

\begin{tabular}{|l|l|}
\hline Anatomic Location & Total $\mathbf{n}(\%)$ \\
\hline Kidney & \\
Left & $43(21.3)$ \\
Right & $39(19.3)$ \\
Both & $14(6.9)$ \\
\hline Ureter & \\
Left & $33(16.3)$ \\
Right & $28(13.9)$ \\
Both & $1(0.5)$ \\
\hline Kidney and Ureter & \\
Both Kidneys and Left Ureter & $9(4.5)$ \\
Both Kidneys and Right Ureter & $1(0.5)$ \\
Right Kidney and Right Ureter & $6(3.0)$ \\
Right Kidney and Left Ureter & $2(1.0)$ \\
Left Kidney and Right Ureter & $5(2.5)$ \\
Left Kidney and Left Ureter & $5(2.5)$ \\
\hline Urinary bladder & $16(7.9)$ \\
\hline
\end{tabular}


Table 4 Types of Procedure Performed in Patients with Urolithiasis at St. Paul's Hospital Millennium Medical College, Addis Ababa, Ethiopia, from July 2016 to December 2017

\begin{tabular}{|c|c|c|c|}
\hline \multirow{2}{*}{$\begin{array}{l}\text { Diagnosis } \\
\text { Renal Stone }\end{array}$} & \multicolumn{2}{|l|}{ Procedure } & \multirow{4}{*}{$\begin{array}{l}\text { Total n (\%) } \\
34(16.8) \\
21(10.4) \\
14(6.9)\end{array}$} \\
\hline & Open & Pyelolithotomy & \\
\hline & & Nephrolithotomy & \\
\hline & & Nephrectomy & \\
\hline & Endoscopy & Ureterorenoscopy & $17(8.4)$ \\
\hline & & Percutaneous Nephrolithotomy & $5(2.5)$ \\
\hline & Combined & Pyelolithotomy and Ureterorenoscopy & $4(2.0)$ \\
\hline & & Nephrolithotomy and Ureterorenoscopy & $\mathrm{I}(0.5)$ \\
\hline \multirow[t]{5}{*}{ Ureteric Stone } & Open & Ureterolithotomy & $3(1.5)$ \\
\hline & & Nephrectomy & $I(0.5)$ \\
\hline & Endoscopy & Ureterorenoscopy & $56(27.7)$ \\
\hline & & Laparoscopic Ureterolithotomy & $I(0.5)$ \\
\hline & Combined & Ureterolithotomy and Ureterorenoscopy & $I(0.5)$ \\
\hline \multirow[t]{6}{*}{ Renal and Ureteric Stone } & Open & Nephrolithotomy & $2(1.0)$ \\
\hline & & Pyelolithotomy & $I(0.5)$ \\
\hline & Endoscopy & Ureterorenoscopy & $21(10.4)$ \\
\hline & Combined & Nephrolithotomy and Ureterorenoscopy & $2(1.0)$ \\
\hline & & Pyelolithotomy and Ureterorenoscopy & $\mathrm{I}(0.5)$ \\
\hline & & Nephrolithotomy and Laparoscopic Ureterolithotomy & $I(0.5)$ \\
\hline \multirow[t]{2}{*}{ Urinary Bladder Stone } & Open & Cystolithotomy & $12(5.9)$ \\
\hline & Endoscopy & Cystolitholapaxy & $4(2.0)$ \\
\hline
\end{tabular}

Table 5 Intra- and Postoperative Complications in Patients with Urolithiasis at St. Paul's Hospital Millennium Medical College, Addis Ababa, Ethiopia, from July 2016 to December 2017

\begin{tabular}{|l|l|l|l|}
\hline Intraoperative Complication & Total $\mathbf{n}(\%)$ & Postoperative Complication & Total $\mathbf{n}(\%)$ \\
\hline No complication & $\mathrm{I} 86(92.1)$ & No complication & $\mathbf{1 7 6 ( 8 7 . 1 )}$ \\
\hline Stone migration & $9(4.5)$ & Surgical site infection & 10(5.0) \\
\hline Bleeding & $4(2.0)$ & Prolonged urine leak & $8(4.0)$ \\
\hline Adjacent organ injury* & $2(1.0)$ & Renal failure & $3(1.5)$ \\
\hline Ureteric perforation & $\mathrm{I}(0.5)$ & Urosepsis & $2(1.0)$ \\
\cline { 2 - 4 } & & Pneumonia & $2(1.0)$ \\
\cline { 2 - 4 } & & Deep vein thrombosis & $\mathrm{I}(0.5)$ \\
\hline
\end{tabular}

Note: $*$ I $0.5 \%$, Descending colon; I $(0.5 \%)$, duodenal injury.

stone, URS $(21,75.0 \%)$ for concomitant stones (renal and ureteric) and cystolithotomy $(12,75.0 \%)$ for urinary bladder stone. Nephrectomy was done to 15 (7.4\%) cases with an indication of pyonephrosis (significant parenchymal destruction) in $3(1.4 \%)$ patients and non-functioning kidney (confirmed IVP) in $12(6.0 \%)$ patients. Overall, URS
$(103,51.0 \%)$ and pyelolithotomy $(40,19.8 \%)$ were the commonest endoscopic and open procedures done to our patients, respectively. Table 4

Of $40(19.8 \%)$ patients with staghorn stone, 34 (85\%) removed with an open procedure, 5 (12.5\%) endoscopically and $1(2.5 \%)$ with combined intervention. 
Intraoperative and postoperative complications were noted in $16(7.9 \%)$ and $26(12.9 \%)$ patients, respectively. Of these, 5 (2.5\%) patients developed both intra- and postoperative complications. Stone migration $(9,4.5 \%)$ and surgical site infection $(10,5 \%)$ were the commonest complications seen during intraoperative and postoperative periods, respectively (Table 5). Ureter was stented in all patients with stone migration and referred for extra-corpor eal shock wave lithotripsy.

Of the patients, stone removal was complete in 114 $(56.4 \%)$, partially complete in $68(33.7 \%)$, no clearance in 5 $(2.5 \%)$ and it is unknown in $15(7.4 \%)$ patients. By excluding patients with unknown stone clearance status, complete stone clearance was possible in $114(114 / 187,61.0 \%)$ patients.

Death occurred in $3(1.5 \%)$ patients. Renal failure was the cause of death in two patients and the other patient died from multiorgan failure due to sepsis. Mortality was comparable between patients who underwent endoscopic $(1 / 104,1.0 \%)$ and open procedure (1/88, 1.1\%). However, it is much higher when both performed together (1/ $10,10.0 \%)$.

Stone chemical analysis is not done in all patients due to the lack of laboratory setup.

\section{Factors Associated with Stone Clearance}

On bivariate analysis, concomitant use of endoscopy and open procedures, endoscopic procedure and multiple stones were significantly associated with incomplete stone clearance. However, endoscopic procedures (AOR $=4.17 ; 95 \%$ CI $1.57-10.71 ; \mathrm{p}=0.003)$ and stone burden (multiple stones) $(\mathrm{AOR}=8.33 ; 95 \%$ CI $2.53-27.43 ; \mathrm{p}<$ $0.0001)$ remained significantly associated in multivariate analysis (Table 6).

\section{Factors Associated with Operative Complications}

The multivariate analysis identified the presence of comorbid illnesses $(\mathrm{AOR}=2.44 ; 95 \% \mathrm{CI} 1.12-5.31 ; \mathrm{p}=0.024)$ was significantly associated with operative complications. However, on bivariate analysis the type of procedure (concomitant use of endoscopic and open procedure) was significantly associated with operative complications (Table 6).

\section{Discussion}

In line with the global trend, studies reported an increasing prevalence of urolithiasis in the tropical and sub-Saharan
African countries. ${ }^{1,4,5,7,12-14}$ Similarly, a recent Ethiopian study demonstrated a rising trend over the past 13 years (from 2004 to 2017) and becoming a public health issue. ${ }^{5}$ Studies done locally showed that urolithiasis represent $13.6 \%$ to $33.6 \%$ of urologic surgical burden which is consistent with our finding, 30.0\% ${ }^{11,25-27}$ Furthermore, reports from other countries recognized urolithiasis among the major reasons of urologic surgical admission. ${ }^{2,3,14}$

Worldwide, the estimated male to female ratio of urolithiasis ranges from 1.5 to $2.5: 1{ }^{7}$ Comparable with this, our study and others also confirmed urolithiasis as a male predominant disease. $^{2,4,5,9,10,12,13,15,25,26,28-30}$ Males are assumed to be susceptible to stone formation for reasons such as lithogenic effect of testosterone, uro-genital anatomy which is prone to stasis and engagement in strenuous work which results in dehydration unless adequately replaced. ${ }^{14,19,24,31}$ The limited opportunity of women to go to a health facility in our setup was also mentioned as a factor for the male predominance in urolithiasis. ${ }^{5}$ On the other hand, recent evidences showed a narrowing of gender gap related to changes in diet and increment in rates of diabetes and obesity. ${ }^{6,7,12}$ More than two third of our patients were between the 3rd and 5th decade of life and the occurrence of stones decreases with age. This holds true in reports from our country and elsewhere. ${ }^{2,5,9,11,13,16,25,29}$ In contrast to this, studies from USA, Japan and Nigeria found out that calculi are frequent in the 5th and 6th decade of life. ${ }^{1,12,32}$ This variation may be explained by a difference in study subjects and geographic location. As stone formation is related with comorbid illness, death at an early age might also attribute to this discrepancy. ${ }^{1}$ Moreover, the higher life expectancy and advanced care in developed nations might contribute to the difference.

Our review and a report by Hounnasso et al witnessed a delayed presentation of patients, 16 months and 5 months, respectively. ${ }^{2}$ This may reflect the lack of access to essential surgical care and less public awareness to urologic disease in the sub-Saharan African countries. ${ }^{22}$ Authors reported flank pain, hematuria and dysuria as the main presenting symptoms of urolithiasis, which is also the case in our study. ${ }^{2-4,12,14,25,30}$ Apart from this, a study conducted by Odzebe et al and Rimtebaye et al found a high rate of acute urinary retention in their review $(26.5 \%$ and $28.7 \%)$. ${ }^{3,21}$ This variation can be explained by the high incidence of lower tract stone and obstructive conditions in their patients. Literature reported an increased risk of urinary stone disease in individuals with associated conditions such as diabetes and hypertension. ${ }^{7,33}$ Either or both of these conditions were seen 
Table 6 Factors Associated with Stone Removal and Operative Complications in Patients with Urolithiasis at St. Paul's Hospital Millennium Medical College, Addis Ababa, Ethiopia, from July 2016 to December 2017

\begin{tabular}{|c|c|c|c|c|}
\hline \multirow[t]{2}{*}{ Variables } & \multicolumn{2}{|c|}{ Stone Clearance } & \multirow{2}{*}{$\begin{array}{l}\text { Crude Odds } \\
\text { Ratio }(95 \% \mathrm{Cl})\end{array}$} & \multirow{2}{*}{$\begin{array}{l}\text { Adjusted } \\
\text { Odds Ratio }(95 \% \mathrm{Cl})\end{array}$} \\
\hline & Incomplete & Complete & & \\
\hline \multicolumn{5}{|l|}{ Duration of Illness } \\
\hline$\leq 1$ year & 62 & 94 & I & \\
\hline >lyear & 11 & 20 & $0.83(0.37-1.86)$ & \\
\hline \multicolumn{5}{|l|}{ Location } \\
\hline Kidney & 31 & 58 & $0.27(0.63-1.14)$ & \\
\hline Ureter & 26 & 33 & $0.39(0.90-1.73)$ & \\
\hline Kidney and Ureter & 10 & 20 & $0.25(0.5 I-I .2 I)$ & \\
\hline Bladder & 6 & 3 & I & \\
\hline \multicolumn{5}{|l|}{ Comorbid illness } \\
\hline No & 53 & 81 & 1 & \\
\hline Yes & 20 & 33 & $0.93(0.48-1.78)$ & \\
\hline \multicolumn{5}{|l|}{ Stone Burden } \\
\hline Single & 30 & 61 & 1 & 1 \\
\hline Multiple & 36 & 21 & $3.49(1.74-6.97) * *$ & $8.33(2.53-27.43) * *$ \\
\hline Staghorn & 7 & 32 & $0.44(0.18-1.12)$ & $1.60(0.39-6.52)$ \\
\hline \multicolumn{5}{|l|}{ Type of Procedure } \\
\hline Open Surgery & 17 & 62 & 1 & 1 \\
\hline Endoscopic & 51 & 48 & $3.87(1.99-7.54) * *$ & $4.17(I .57-10.7 I) * *$ \\
\hline \multirow[t]{3}{*}{ Both } & 5 & 4 & $4.56(1.10-18.86) *$ & $2.65(0.53-13.23)$ \\
\hline & \multicolumn{2}{|c|}{ Operative Complications } & & \\
\hline & Yes & No & & \\
\hline \multicolumn{5}{|l|}{ Age } \\
\hline$\leq 50$ & 28 & 139 & $1.72(0.73-4.06)$ & \\
\hline$>50$ & 9 & 26 & 1 & \\
\hline \multicolumn{5}{|l|}{ Sex } \\
\hline Male & 24 & 111 & I & \\
\hline Female & 13 & 54 & $1.11(0.53-2.35)$ & \\
\hline \multicolumn{5}{|l|}{ Stone burden } \\
\hline Single & 13 & 82 & I & \\
\hline Multiple & 16 & 51 & $1.98(0.88-4.45)$ & \\
\hline Staghorn & 8 & 32 & $1.58(0.60-4.16)$ & \\
\hline \multicolumn{5}{|l|}{ Comorbid illness } \\
\hline No & 20 & 126 & 1 & 1 \\
\hline Yes & 17 & 39 & $2.75(1.31-5.75) *$ & $2.44(|| 2-5.31) *$. \\
\hline \multicolumn{5}{|l|}{ Location } \\
\hline Kidney & 21 & 75 & $1.21(0.32-4.66)$ & \\
\hline Ureter & 8 & 54 & $0.64(0.15-2.76)$ & \\
\hline Kidney \& Ureter & 5 & 23 & $0.94(0.10-4.59)$ & \\
\hline Bladder & 3 & 13 & 1 & \\
\hline \multicolumn{5}{|l|}{ Procedure } \\
\hline Endoscopy & 14 & 90 & 1 & \\
\hline Open surgery & 19 & 69 & $1.77(0.83-3.78)$ & \\
\hline Both & 4 & 6 & $4.29(1.07-17.12) *$ & \\
\hline
\end{tabular}

Notes: *Significantly associated at $\mathrm{p}$-value $<0.05 . * *$ Significantly associated at $\mathrm{p}$-value $>0.005$. 
in $24.7 \%$ patients in our study, $10.8 \%$ in Benin and $17 \%$ in Nigeria. ${ }^{2,13}$ It is well demonstrated that insulin resistance results in low urine $\mathrm{pH}$ through impaired kidney ammoniagenesis which in turn leads to stone formation. However, data on the link between hypertension and urinary stone is inconsistent. $^{7,33}$ On the other hand, a dietary approach to stop hypertension (DASH) was found to decrease the risk of kidney stone formation. ${ }^{34}$ In this study, $4 \%$ of the subjects reported HIV-infection which may increase the risk of stone formation related to the underlying metabolic abnormality and adverse effect of indinavir treatment. ${ }^{35}$

The choice of diagnostic imaging for urolithiasis is non-contrast-enhanced CT-scan (NCCT) which has a sensitivity and specificity of $93.1 \%$ and $96.6 \%$, respectively. ${ }^{36,37}$ However, its use in sub-Saharan African countries is limited due to its availability. ${ }^{16}$ In agreement with this, our study and others reported ultrasound and IVP as the main diagnostic imaging performed. ${ }^{2,3,14}$ Even if ultrasound has low sensitivity to identify urinary stones, it is the initial choice of imaging for reasons such as accessibility, affordability and safety. ${ }^{3,12,16,36}$ In our study NCCT was utilized in $19.8 \%$ of the patients which is very low as compared with a study from Kenya (81\%) and Nigeria $(57.9 \%)^{4,12}$ The high burden of patients from other disciplines and frequent malfunction maybe the reason for the low use of NCCT in our patient's diagnosis.

If left untreated, stones may lead to damage by causing obstruction and persistent infection. A review of literature done in Africa by Cassell et al showed hydronephrosis and infection are among the commonly reported clinical presentation of urolithiasis. ${ }^{16}$ This is consistent with the higher rate of hydronephrosis seen in our patients $(73.3 \%)$ and other studies done locally by Adualem et al $(63 \%)$ and Teferi et al $(78.2 \%) .{ }^{11,25}$ The possible reason for this could be the late presentation of patients preventing early diagnosis and prompt treatment. Even if renal failure at presentation is lower in our review (4.9\%) than the reports of Hounnasso et al $(8.8 \%)$, Adualem et al $(15 \%)$ and Teferi et al (43.6\%), it demands further evaluation with a better study design. . $^{211,25}$

Literature reported the migration of stone location from the lower tract to the upper due to changing global climate and socioeconomic status. ${ }^{6-8,33}$ Our study and other similar studies from Ethiopia and elsewhere found the upper tract as the frequent anatomic site of urolithiasis. $^{2,4,5,10,11,15,25,28,30,38}$ In contrast to this, Nigerian authors identified the urinary bladder as the commonest location which was attributed by its endemicity and higher rate of poorly treated bladder out late obstruction in their study. ${ }^{12-14,17}$ Alemu also demonstrated the common occurrence of urinary bladder stones in Mekelle, northern Ethiopia. ${ }^{26}$ This could be partly due to the difference in the setup in which lower tract stones tend to be managed in a low resource setting and complex stones being referred to higher health facilities. The recent study identified a higher number of staghorn stones than studies done in Ethiopia (10\%), Senegal $(5.6 \%)$ and Iran $(2.5 \%))^{9,11,20}$ This might indicate the higher rate of underlying infectious causes in our patients. In contrary to other African studies, our review and a recent Ethiopian study reported that the left kidney was more commonly affected than the right one. 5,16,28

Unlike the well revolutionized surgical treatment of urolithiasis in the western world, open stone surgery still remains the mainstay of approach in most developing nations. $^{2,3,14,16,20,24,30}$ The recently available minimal invasive treatment options include extracorporeal shock wave lithotripsy (ESWL), URS, percutaneous nephrolithotomy (PCNL) and laparoscopic approaches ${ }^{16,30,39}$ The rate of open surgery in the developed countries ranged from $0.47-5 \%$ and it is reserved for indications such as complex stone disease, concomitant anatomical abnormalities, failure of minimal invasive treatments, concurrent open surgery, severe limb contractures, and patient choice. ${ }^{15,39}$ Authors from Africa reported the rate of endourologic procedures ranged from $30.5-52.8 \%$ which is encouraging and in line with our review (51.5\%). ${ }^{11,14,16,25}$ Lack of endoscopic equipment's, sustainable supply, maintenance, training in urology and delayed patient presentation were the main factors mentioned for the high rate of open surgery in developing nations. $^{22,23,25,38}$ The reported rate of nephrectomy for stone disease, in Africa urologic centers, ranged from $1.9-17.9 \%{ }^{16}$ Even if the findings of our study $(7.4 \%)$ and other studies done in Ethiopia by Adualem et al $(8 \%)$ and Teferi et al (11.5\%) were within this range, it necessitates urgent attention. ${ }^{11,25}$ A study from Pakistan identified a low rate of nephrectomy $(2.33 \%)$ due to the low incidence of pyonephrosis and a better treatment plane. ${ }^{30}$

The overall rate of operative complications in this review was $18.3 \%$ and it was less frequent in endoscopic procedures $(15.5 \%)$ than open stone surgeries $(27.5 \%)$. Moreover, the presence of comorbid illness was associated with increased odds $(\mathrm{p}=0.024)$ of these complications than their respective groups. In contrast to this, similar studies in Ethiopia reported a higher rate, ranging from 24-30\%. ${ }^{11,25,38}$ This discrepancy might be 
explained by the higher rate of open stone surgery in their study. However, the complications associated with open stone surgeries were higher in our cohort than studies elsewhere, ranging from 1.7-22.5\%. ${ }^{2,3,13,14,21,39}$ The higher number of comorbid illnesses in our study may account for the difference. Stone migration and SSI were the most frequent operative complications seen in our patients and others. ${ }^{2,3,11,13,14,25,38}$ Cassell et al reported the rate of surgical site infection in open stone surgeries from $0.8 \%$ to $15 \%$ which is parallel with our findings. ${ }^{16}$ This study (1.0\%), the ureteroscopy global study (0.7-$1.6 \%$ ) and a similar study done in Ethiopia (1.2\%) found similar rates of ureteric perforation following URS. ${ }^{19,40}$

In our analysis, the overall complete stone clearance was $61.0 \%, 78.5 \%$ in open stone surgery and $48.5 \%$ in endoscopic procedures, which is lower than the report by Adualem et al (77.4\%) done in our country. ${ }^{11}$ This could be due to the higher rate of endoscopic interventions in our study, hence multiple stones $(p<0.0001)$ and endoscopic procedures $(p=0.003)$ were significantly associated with incomplete stone clearance. In contrast to this, endoscopic interventions in other reports achieved $>85 \%$ complete stone clearance. ${ }^{19,28}$ Even if this variation needs further exploration, the potential contributing factors include delayed patient presentation, constraints of appropriate instrument and expertise.

The retrospective nature of the study was the major limitation, resulting in missed data of major parameters such as stone size, risk factors and follow up of patients. The other drawback was the absence of data regarding stone chemical analysis due to the lack of laboratory setup. Otherwise, this study provided pertinent findings regarding presentation, surgical management and outcome of urolithiasis which helps to improve the urologic care in our patients.

In conclusion, the clinical presentation of urolithiasis in our study was not different from studies elsewhere. However, we observed a delayed duration of presentation. Endoscopic interventions are emerging in our set up provided that it is significantly associated with incomplete stone clearance. Operative complications were higher in open stone surgery than endoscopic interventions and significantly associated with the presence of comorbid conditions. Adequate perioperative optimization of patients with comorbid illnesses, implementing effective strategies to improve endourologic platform and increasing public awareness regarding urinary stone disease, were the major issues which should be addressed in our unit. Moreover, a set-up to analyze stone composition needs to be established for preventive care.

\section{Disclosure}

The authors report no conflicts of interest in this work.

\section{References}

1. Romero V, Akpinar H, Assimos DG. Kidney stones: a global picture of prevalence, incidence, and associated risk factors. Rev Urol. 2010;12(2-3):e86.

2. Hounnasso PP, Avakoudjo JD, Paré AK, et al. Symptomatic urinary lithiasis: epidemiology and management at urology department of university hospital of Cotonou. Open $J$ Urol. 2015;5(02):7. doi:10.4236/oju.2015.52002

3. Rimtebaye K, Sillong FD, Tashkand AZ, Kaboro M, Niang L, Gueye SM. Urolithiasis: diagnostic and therapeutic aspects in urology department of n'djamena in chad. Open J Urol. 2015;5(11):199. doi:10.4236/oju.2015.511032

4. Wathigo FK, Hayombe A, Maina D. Urolithiasis analysis in a multiethnic population at a tertiary hospital in Nairobi, Kenya. BMC Res Notes. 2017;10(1):158. doi:10.1186/s13104-017-2474-3

5. Alelign T, Debella A, Petros B. Trends in the magnitude of urolithiasis surgery in Ethiopia: A 13-years retrospective data from St paulos referral hospital. Ethiopian Medical J. 2020;58:03.

6. McDougal WS, Wein AJ, Kavoussi LR, Partin AW, Peters CA. Campbell-walsh urology 11th Edition Review E-Book. Elsevier Health Sciences; 2015 Sep 25.

7. Sorokin I, Mamoulakis C, Miyazawa K, Rodgers A, Talati J, Lotan Y. Epidemiology of stone disease across the world. World $J$ Urol. 2017;35(9):1301-1320.

8. López M, Hoppe B. History, epidemiology and regional diversities of urolithiasis. Pediatric Nephrology. 2010;25(1):49. doi:10.1007/ s00467-008-0960-5

9. Noshad H, Ahmadpour F, Soltanpour B, Ghojazadeh M. Study of renal stones complications in 200 patients in Tabriz, Iran. $J$ Research Clinical Medicine. 2014;2(4):187-192.

10. Qaader DS, Yousif SY, Mahdi LK. Prevalence and etiology of urinary stones in hospitalized patients in Baghdad. Eastern Mediterranean Health J. 2006;12(6):853-861.

11. Adualem. D, Gidena G. Admission patterns and management of urolithiasis; a hospital based study in Tikur Anbessa Hospital (TASH)", Addis Ababa, Ethiopia. East Cent Afri J Surg. 2014;19(3).

12. Omisanjo O, Bioku M, Williams $\mathrm{O}$, Akinola $\mathrm{O}$, Balogun $\mathrm{F}$, Ikuerowo S. A 5-year review of the presentation and management of urolithiasis in a nigerian teaching hospital. $J$ Surgery. 2019;7 (5):143-147. doi:10.11648/j.js.20190705.16

13. Odoemene CA, Okere PC, Ugonabo MC. Ureterolithiasis: management in an environment with limited facilities. Niger J Clin Pract. 2017;20(5):622-628. doi:10.4103/njcp.njcp_14_16

14. Abubakar BM, Abubakar A, Suleiman IE, Makama BS, Abdulhafeez AA, Gashua MG. Pattern of presentation and management of urolithiasis at federal medical centre, nguru, nigeria. Bo Med J. 2017;14:1.

15. Yu DS, Yang YT, Lai CH. Epidemiology and treatment of inpatients urolithiasis in Taiwan. Formosan J Surgery. 2016;49(4):136-141. doi:10.1016/j.fjs.2016.04.003

16. Cassell III A, Jalloh M, Ndoye M, et al. Surgical management of urolithiasis of the upper tract-current trend of endourology in Africa. Research Reports Urol. 2020;12:225. doi:10.2147/RRU.S257669

17. Emokpae MA, Gadzama AA. Anatomical distribution and biochemical composition of urolithiasis in Kano, northern Nigeria. Int J Biological Chemical Sciences. 2012;6(3):1158-1166. 
18. Zumstein V, Betschart P, Abt D, Schmid HP, Panje CM, Putora PM. Surgical management of urolithiasis-a systematic analysis of available guidelines. BMC Urol. 2018;18(1):25. doi:10.1186/s12894-0180332-9

19. Castro EP, Osther PJ, Jinga V, et al., CROES Ureteroscopy Global Study Group. Differences in ureteroscopic stone treatment and outcomes for distal, mid-, proximal, or multiple ureteral locations: the clinical research office of the Endourological Society ureteroscopy global study. Eur Urol. 2014;66(1):102-109. doi:10.1016/j. eururo.2014.01.011

20. Kane R, Diallo Y, Niang L, et al. Upper urinary tract calculi in senegal: a comparative study between open surgery and endoscopy, a review of 89 cases. Open J Urol. 2015;5(09):142. doi:10.4236/ oju.2015.59022

21. Odzebe AS, Bouya PA, Berthe HJ, Omatassa FR. Open surgery of the urinary tract calculi at the university hospital of Brazzaville: analysis of 68 cases. Mali Med. 2010;25(2):32-35.

22. Olapade-Olaopa EO, Onawola KA. Challenges for urology in sub-Saharan Africa in 2006. J Men's Health Gender. 2006;3 (1):109-116. doi:10.1016/j.jmhg.2006.01.004

23. Biyani CS, Bhatt J, Taylor J, Gobeze AA, McGrath J, MacDonagh R. Introducing endourology to a developing country: how to make it sustainable. J Clin Urol. 2014;7(3):202-207. doi:10.1177/ 2051415813514971

24. Mahamat MA, Diarra A, Kassogué A, et al. Renal colic: epidemiological, clinical etiological and therapeutic aspects at the urology department of the national reference general hospital of n'djamena (Chad). Open J Urol. 2020;10(02):25. doi:10.4236/oju.2020.102004

25. Teferi GT, Kifle AT. Management of urolithiasis at hawassa university referral hospital, Ethiopia: A retrospective, descriptive study. East Central African J Surgery. 2020;25:2.

26. Alemu MH. Pattern of urinary tract stone diseases in Mekelle, Ethiopia. Ethiop Med J. 2008;46(3):237-241.

27. Feldhaus I, Temesgen GW, Laytin A, Odisho AY, Beyene AD. Uncovering the burden of urologic disease: admissions patterns at the main teaching hospital of Ethiopia. East Central African J Surgery. 2016;21(3):77-84. doi:10.4314/ecajs.v21i3.13

28. Ngugi PM, Magoha GA, Kiptoon D. Urolithiasis in Nairobi, Kenya. East Afr Med J. 2010;87:10.
29. Freeg MA, Sreedharan J, Muttappallymyalil J, et al. A retrospective study of the seasonal pattern of urolithiasis. Saudi j Kidney Diseases Transpl. 2012;23(6):1232.

30. Memon JM, Athar MA, Akhund AA. Clinical pattern of urinary stone disease in our setting. Ann King Edward Medical University. 2009;15 (1): 17 .

31. Lee YH, Huang WC, Huang JK, Chang LS. Testosterone enhances whereas estrogen inhibits calcium oxalate stone formation in ethylene glycol treated rats. J Urol. 1996;156(2):502-505. doi:10.1016/S00225347(01)65914-7

32. Thun MJ, Schober S. Urolithiasis in Tennessee: an occupational window into a regional problem. Am J Public Health. 1991;81 (5):587-591. doi:10.2105/AJPH.81.5.587

33. Trinchieri A. Epidemiology of urolithiasis: an update. Clinical Cases Mineral Bone Metabolism. 2008;(2):101.

34. Taylor EN, Fung TT, Curhan GC. DASH-style diet associates with reduced risk for kidney stones. J Am Society Nephrol. 2009;20 (10):2253-2259. doi:10.1681/ASN.2009030276

35. Nadler RB, Rubenstein JN, Eggener SE, Loor MM, Smith ND. The etiology of urolithiasis in HIV infected patients. J Urol. 2003;169 (2):475-477. doi:10.1016/S0022-5347(05)63936-5

36. Turk C, Neisius A, Petrik A, Seitz C,Skolarikos A, Tepeler A, Thomas K. EAU guidelines on urolithiasis 2015. Available from: Uroweb.org. Accessed September 10, 2020.

37. Niemann T, Kollmann T, Bongartz G. Diagnostic performance of low-dose CT for the detection of urolithiasis: a meta-analysis. American j Roentgenol. 2008;191(2):396-401. doi:10.2214/ AJR.07.3414

38. Negussie T, Negash S, Derbew M. Surgical management of urinary tract stones in children: experience from tikuranbessa hospital, addis ababa, ethiopia. ethiop Med J. 2018;56:3.

39. Honeck P, Wendt-Nordahl G, Krombach P, et al. Does open stone surgery still play a role in the treatment of urolithiasis? Data of a primary urolithiasis center. J Endourol. 2009;23(7):1209-1212. doi:10.1089/end.2009.0027

40. Andualem D, Be-ede L, Mulat T, Samodi L. Ureteroscopy in a resource limited setting: the tikur anbessa general specialized hospital experience in addis ababa, ethiopia. East Central African J Surgery. 2012;17(3):87-91.
Research and Reports in Urology

\section{Publish your work in this journal}

Research and Reports in Urology is an international, peer-reviewed, open access journal publishing original research, reports, editorials, reviews and commentaries on all aspects of adult and pediatric urology in the clinic and laboratory including the following topics Pathology, pathophysiology of urological disease; Investigation and treatment of urological disease; Pharmacology of drugs used for the treatment of urological disease. The manuscript management system is completely online and includes a very quick and fair peer-review system, which is all easy to use. Visit http://www.dovepress.com/ testimonials.php to read real quotes from published authors. 